\title{
Understanding Today's Online GIS User Through the Lens of a WorldMap Survey
}

\section{Citation}

Guan, Weihe Wendy, Alenka Poplin, and Benjamin G. Lewis. 2015. “Understanding Today's Online GIS User Through the Lens of a WorldMap Survey." Transactions in GIS 19 (3) (June): 417-438. doi:10.1111/tgis.12150.

\section{Published Version}

doi:10.1111/tgis.12150

\section{Permanent link}

http://nrs.harvard.edu/urn-3:HUL.InstRepos:26847182

\section{Terms of Use}

This article was downloaded from Harvard University's DASH repository, and is made available under the terms and conditions applicable to Other Posted Material, as set forth at http:// nrs.harvard.edu/urn-3:HUL.InstRepos:dash.current.terms-of-use\#LAA

\section{Share Your Story}

The Harvard community has made this article openly available.

Please share how this access benefits you. Submit a story.

\section{Accessibility}




\title{
Understanding today's online GIS user through the lens of a WorldMap survey
}

\author{
Weihe Wendy Guan ${ }^{1}$, Alenka Poplin ${ }^{2}$ and Benjamin G. Lewis ${ }^{3}$
}

\begin{abstract}
WorldMap is an open source online mapping application which aims to lower barriers for scholars who wish to visualize, analyze, organize, present, and publish mapped information. In late 2013, two hundred and ninety respondents among the eight thousand registered users participated in an online survey in which they described their activities, purposes, experiences, and preferences regarding the system. Participants also described their professional background, GIS skill level, age, gender, and country of work. This study analyzes the results of the survey, by summarizing the responses to each question independently and by examining the relationships and dependencies of these answers across the different questions to try to better understand why users responded the way they did. The study is based on the user-centered design (UCD) approach. We aim to use the survey results to improve our understanding of user demographics and needs. Findings from this study will be used to guide WorldMap improvements, and we hope the findings will also shed light on the broader requirements of online GIS users.
\end{abstract}

Keywords: Online GIS, WorldMap, user-centered design, web mapping, users survey

\section{Introduction}

Geographic Information Systems (GIS) have flourished in the online environment in recent years, expanding the availability of GIS tools from being the domain of small number of trained professionals to now being accessible by anyone with access to the internet.. Many GIS platforms have come online in recent years including ArcGIS Online, Google Maps Engine, GeoCommons, MapBox, OpenStreetMap, WorldMap, etc. These and other systems have made creating, interpreting, and mapping locational data easier and more intuitive, enabling people from all walks of life to create their own datasets and maps online. Most users now expect to come to a browser and get meaningful mapping work done without much training. Thus online GIS systems are pulled to two directions: the professionals needing a rich set of functions, and novice users who want simplicity and ease of use. Building a system useful to both is a major challenge.

This study takes WorldMap as a test case. As described in Guan et al. (2012) WorldMap is an online mapping application designed and built by the Center for Geographic Analysis (CGA) at Harvard University. It is made available to anyone in the world with access to the Internet. It allows users to upload their own data, mash their data up with data found online, and create interactive maps online. From a web browser, people without prior experience with GIS can visit the WorldMap website (http://worldmap.harvard.edu), browse among the thousands of maps and layers composed by other users, or freely register for a user account to start composing their own maps using data layers stored in WorldMap, those provided by

\footnotetext{
${ }^{1}$ Corresponding author, Center for Geographic Analysis, Harvard University, 1737 Cambridge St., Suite 350, Cambridge, MA 02138 USA. Email: wguan@cga.harvard.edu

${ }^{2}$ Iowa State University

${ }^{3}$ Center for Geographic Analysis, Harvard University
} 
remote map servers, or those uploaded from their local hard drives. Users can choose to share their maps and uploaded data sets with others or keep them private.

WorldMap aims to lower barriers for scholars who wish to visualize, analyze, organize, present, and publish mapped information. The system is open source and an instance is hosted at Harvard, free for researchers to use.. The system enables academics, researchers, and the general public to discover, visualize, investigate, and communicate within a spatial framework. Since WorldMap began in 2011, more than half a million people have used the system, initiating thousands of research studies, and in the process made many thousands of new map layers available to the international community of scholars.

In late 2013, the authors invited all registered users of WorldMap to participate in an online survey. The survey was designed to capture data on both user experience and user demographics. It is condensed into ten questions; mostly multiple choice, to allow users to complete the survey quickly. A total of 290 responses were received in one month, about $3.55 \%$ of the user population.

This empirical study analyzes relationships between the users' demographic, professional and technical backgrounds and their activities and experiences on WorldMap as reported in the survey. It attempts to answer questions such as "Do people with a science or engineering background find WorldMap easier to use than those in the humanities?" "What kinds of users use the online help?" "Does the help document improve their user experience?" "Who tends to contribute data to the system?" "Who tends to care about data quality?" "Who demands indepth analytical functions?" "Who is engaged in collaboration?" The findings are useful for guiding WorldMap improvements, and also shed light on the demographics of the burgeoning online GIS user community.

The goal of this paper is two-fold. First, we aim to contribute to the discussion and regarding the usability of online interactive mapping systems and we hope to expand our understanding of issues heterogeneous users have with these systems. Second, we aim at implementing a user-centered design approach in developing and improving the online mapping system WorldMap. In the following section we present research on the user-centered design of mapping systems and the experience gained by GIScience researchers while implementing it in a variety of case studies.

\section{User-centered design of mapping systems}

The importance of users, their experience with information technologies (Krug 2000; McCarthy and Wright 2004), and their emotions experienced while using them (Norman 2004) is the main focus of research on human-computer interaction and usability of software systems. Human-computer interaction (HCI) developed as a discipline that is "concerned with the design, evaluation and implementation of interactive computing systems for human use and with the study of major phenomena surrounding them" (Hewett et al. 2002). It focuses particularly on enhancing the quality of interactions between humans and computer systems (Meyers et al. 1996; Butler 1996). Paying close attention to the users and their experience is central for the creation of successful, user-friendly, acceptable and useful mapping systems.

GIScience researchers substantially contributed to a better understanding of humancomputer interaction and the user's interaction with maps. Earlier research on usability of mapping systems (Medyckyj-Scott 1993; Nygers et al. 1995) focused on the use of geographical information systems (GIS) by expert, GIS knowledgeable specialist users. Nowadays GIS users vary in their GIS knowledge, education, age, and their demographic background, as shown in our survey. Many peopleregularly use maps at their work, and for navigation,. Accommodating such a wide spectrum of needs is a challenge. Some recent 
studies related to usability of interactive maps (Hakley and Tobón 2003; Hakley and Zafiri 2008; Poplin 2014) concentrate on heterogeneous, non-GIS expert users and their experience with mapping systems. Others concentrate on cognitive aspects of interaction with online maps. Their research is motivated by "the desire to improve the usability, efficiency, equity, and profitability of a wide variety of geographic information and GIS" (Montello 2009, p. 2825). Novel research on usability of interactive mapping systems has to take into account a number of factors such as the requirements of the users (Adrienko et al. 2002; Hakley and Tobón 2003), designing better map interfaces (Harrower and Sheesley 2005; Roth and Harrower 2008), the capabilities and limitations of the mapping systems (McEachren and Kraak 2001; Nivala et al. 2007; Nivala et.al. 2008; Edsall 2009), visualization methods (Koua et al. 2006; Edsal et al. 2009), the types of support the system can provide, where it can be provided most effectively, understanding dynamic visualization (Hegarty 2004), cognitive aspects (Hegarty 2004; Montello 2009; Hegarty 2013), and emotional and other responses of the user using interactive mapping systems. It also uses novel techniques exploring the interaction of users with maps, such as for example eye-tracking (Fabrikant et al. 2008; Çöltekin et al. 2009).

The design and development of new systems, products or processes that place the potential users in the center is referred to as "user-centered design" (UCD). Norman (2002) in his book "The Design of Everyday Things" describes UCD as the design based on the needs of the user, leaving aside aesthetics or emotional responses which he considers secondary issues. It is designed as a multi-stage, interactive process focused on needs, wants and the limitations of the users. It requires designers to foresee and analyze ways the users are going to use the product/system, such as in which cases and situations they might have problems with it. It can also include testing of the system's usability, validity, and prototype implementation with regard to the users' behavior and interaction with the system. Testing is usually executed before the final implementation in order to learn about the first-time user experience and their learning curve.

Multiple scholars within GIScience have implemented the user-centered design approach (Slocum et al. 2003; Fuhrmann and Pike 2005; Robinson et al 2005; Roth 2010). Hakley and Tobón (2003) explored the usability of Public Participation Geographical Information Systems (PPGIS) and how a user-centered design approach can be used on the example of the inner London Borough of Wandsworth. They organized a series of workshops and involved local communities and individual residents in a focused discussion about brownfield development. Their HCI and usability evaluation techniques included the use of focused groups, the use of software to record the interactions between the users and the system, verbalization of the user's thoughts regarding the interactions and the development of a task list to guide the process, the use of tasks or scenarios to obtain information about users' performance and attitudes towards the system, and chauffeurs that 'drove' the software. In their research they concluded that tools that allow interactive and dynamic exploration of spatial data and user's perception of visual stimuli and the type of tasks that this system can support is yet to be fully understood. The authors also conclude that "Probably the most important lesson from our project is that ease of use and user friendliness are characteristics of software that are more elusive than they first seem to be". Eleven years later Poplin (2015) in her research on interaction with online interactive maps, using experiments involving heterogeneous users, concludes that some of the seemingly simple tasks can still represent substantial problems for average users. Tasks considered to be rather difficult and too complex include seemingly simple ones such as "drawing a line" on a map, "finishing a line", or "turning on a satellite image", among others. 
In the following section we present how we implemented some of the principles of usercentered design in the process of WorldMap development. WorldMap has been designed and implemented based on the demands from users whom the development team has communicated with. But the user base has expanded significantly beyond CGA's direct reach. Based on the principles of the user-centered design, we designed an online survey which was sent to registered WorldMap users. Our intention is to digest the survey results and discover information that will help us improve WorldMap, and help others who wish to design online mapping systems. Furthermore we discuss which functionalities of the mapping system represent difficulties for the users and how the understanding of these difficulties can contribute to improved online mapping systems.

\section{Design of the survey}

The authors designed the survey with the objective of maximizing information capture per response and maximizing the number of responses. Due to the rapid development cycle of the WorldMap platform, a survey can become out of date quickly. In order to attract a significant number of responses quickly, we attempted to minimize the questionnaire length and response time. To accomplish this, the authors used several matrixes of choices, grouping related questions and multiple choice answers. The ten questions we asked were:

1. Please evaluate the difficulty of each WorldMap activity from 1 (very easy) to 4 (very difficult) and 9 (I never used it)

a. Find someone else's map and make use of it

b. Create my own map using data in WorldMap

c. Add my own data to WorldMap and use it in my maps

d. Export my map or data to use in other systems

e. Control access to my materials

f. Find information about data in WorldMap

g. Provide feedback on data quality

h. Other - Please specify

2. Please evaluate the usefulness of each source of help from 1 (very helpful) to 4 (not helpful at all) and 9 (I never used it)

a. Quick start video on the front page

b. The help document available in PDF

c. CGA help service by email or phone

d. WorldMap user forum (Google group)

e. CGA help desk live sessions

f. CGA training classes

g. Other - Please specify

3. Please evaluate the general characteristics of the WorldMap system from 1 (very good, appealing, positive) to 4 (very bad, not appealing, negative) or 9 (no opinion)

a. Response speed

b. Stability

c. The appearance of the system

d. Tools and functions available

e. Ease of use

f. Base map availability

g. Data visualization capability

h. Data creation, data editing

i. Metadata creation and editing

j. Other - Please specify 
4. If you have stopped using WorldMap, please tell us why.
a. Could not log in
b. Could not figure out how to use the system
c. Could not find the data I needed
d. The system was not working
e. I found a better system to meet my needs
f. Other - Please specify

5. What is your profession and discipline?

a. Professions
i. Professor
ii. Student
iii. Research associate, postdoc
iv. Government
v. Business
vi. Non-profit
vii. Citizen scholar, hobbyist
viii. Other - Please specify

b. Disciplines
i. Geography (physical, cultural)
ii. Social science (economics, political science, anthropology, sociology, etc.)
iii. Humanities (history, literature, art, design, etc.)
iv. Design or planning
v. Environmental science
vi. Science
vii. Medicine, health
viii. Information technology
ix. Engineering
x. Other - Please specify

6. What is your main reason for using WorldMap?
a. Teaching
b. Research
c. Job requirement
d. Learning, e.g. course assignments
e. Hobby
f. Other - Please specify

7. What is your level of experience?

a. Geographic Information System (GIS)
i. Regular user
ii. Occasional user
iii. First-time user
iv. Never used

b. WorldMap
i. Regular user
ii. Occasional user
iii. First-time user
iv. Never used

8. How did you first hear of WorldMap?

a. Harvard internal information source

b. A colleague or friend 
c. Internet search

d. Conference or public talk/presentation

e. Published article

f. Other - Please specify

9. What is your age and gender?

a. Age
i. Under 18
ii. $18-25$
iii. $26-45$
iv. $46-65$
v. Over 65

b. Gender
i. Male
ii. Female

10. What is your affiliation?

a. In which organization do you work?

b. In what country do you work?

Excluding question \#10 which requires text strings as the answer, and the "Other - Please Specify" options, there are a total of 231 possible choices provided in the 9 questions at the click of a button. The survey was administered through SurveyMonkey with a basic subscription account. It was opened on November 20, 2013 and closed on December 21, 2013 by which time 290 responses had been received.

\section{Who are the users and how representative are the survey responses?}

WorldMap is an open platform. Anyone with access to a web browser can use it to look for data and view maps (collections of GIS data layers) created by others. Only when someone needs to upload her own local data layers, create her own maps, or is invited by someone else to edit a map or layer, is a registered account required. Registration requires only a valid email address. User profile contents are optional and many users do not build their profile page for one reason or another. Therefore, to reach out to the users, the authors only have a list of the email addresses from the registration record.

After removing duplicate entries, there were a total of 8164 valid email addresses to which the survey invitation was sent. A quick analysis of these email addresses revealed the following statistics:

- Total unique email domains (@aaa.bbb...xxx.yyy.zzz): 1906

- Total unique last-two-level domains (.yyy.zzz): 1585

- Total unique top level domains (.zzz): 87

- Total unique "edu” domains (.yyy.edu): 273

Figure 1 and 2 describe the most common email domains. To some degree, the domains reflect the composition of the users' business sectors and national origins. Only $8 \%$ of all registered WorldMap users use a "harvard.edu" email; and 16\% use an ".edu" email. In addition to the United States, email domains revealed numerous users from the UK, Australia, Canada, Germany, Italy and France.

Figure 1 Most popular last-two-level email domains

Figure 2 Most popular top level email domains 
Among the 290 survey responses, 251 provided their country of work. Figure 3 shows the most popular countries, including USA, Italy, Australia, Spain, Canada, India, Japan, Indonesia, and UK. Even though this is not exactly the same as the percentage and ranking of these countries derived from the email top level domains, the two lists nonetheless share a majority of the top runners.

Figure 3 Main countries of work

Over the past two years, $40 \%$ of WorldMap traffic originated in the US. Since $47 \%$ of survey respondents identify their country as U.S., this provides additional evidence that the survey results are fairly representative of the total WorldMap user population.

\section{Initial review of the responses}

The authors' first attempt at understanding the survey results was to summarize the responses to each of the questions independently. This provides an overall picture of user behaviors, preferences, experiences, backgrounds, and demographic composition. In a later section of this paper, the authors examine the relationships and dependencies of these answers among a subset of different questions, which provides further context for understanding user choices.

\section{Figure 4 Easiness/difficulty of WorldMap activities}

Among the 7 activities included in Question 1, the responses revealed how easy/difficult they are, and how useful they are, as shown in Figure 4 and Table 1.

\section{Table 1 Easiness/difficulty of WorldMap activities}

Because the total number of users responded to each activity are different, it is not straight forward to compare the easiness of these activities by the response counts directly. The authors further summarized the data by adding answers " 1 " and " 2 " together to represent the number of users considering the activity "easy", and adding answers " 3 " and " 4 " together to represent the number of users considering the activity "difficult", and then divided these two numbers to derive the easiness ratio. Similarly, all "easy" and "difficult" answers are added together as "used" and divided by answers "9" which is "not used" to derive the usage ratio. The result is shown in Table 2.

\section{Table 2 Easiness and usefulness of WorldMap activities}

Table 2 shows that "Find information about data in WorldMap" has the highest usage ratio (for every one user who didn't use it, 3.1 users used it), but a relatively low easiness ratio (for every one user who considered it difficult, only 1.5 users considered it easy); while "Control access to my materials" has a relatively low usage ratio (for every one user who didn't use it, only 1.6 users used it), but a higher easiness ratio (for every one user who considered it difficult, 1.8 users considered it easy).

While the "easiness ratio" is for the WorldMap platform only, the "usage ratio" may indicate the general need of the web mapping community. More people are interested in finding data, finding information about these data, creating their own maps on the web, adding their own data to their maps, and controlling access when sharing, but are less interested in downloading data and maps to a different system, or providing feedbacks on someone else's data quality.

While the data shows that about half of the users didn't download data from WorldMap, there is no easy way to distinguish the cause. It could be "not able to", "no need to" or "don't want to". For the small portion of users whom the authors had individual contacts, most of them do have access to other GIS systems, but many prefer not to use them for work they do 
on WorldMap. It is safe to say that in general, users prefer those online GIS systems which allow them to finish their work from beginning to end, rather than those expecting them to jump between tools for common tasks.

Applying the same summary algorithm to questions 2 and 3, the authors derived the helpfulness and usage rate of WorldMap help resources as shown in Table 3, and the favorability and importance of WorldMap characteristics as shown in Table 4.

Table 3 Helpfulness and usage rate of WorldMap help resources

Table 3 shows that a little over half of the users used the online help video and file, and about a quarter used the other help resources. Of those that did try the help resources most found them useful.

\section{Table 4 Favorability and importance of WorldMap characteristics}

WorldMap scored the highest with its stability among the listed properties in this question - for every 1 user who rated stability to be "bad, not appealing, negative", 4.1 users rated it to be "good, appealing, positive". The users cared the most about WorldMap's ease of use - for every 1 user who entered "no opinion", 8.6 users entered some opinion about it. A possible explanation to this is that the WorldMap user community is composed mostly of researchers with little GIS or mapping experience. Unlike to commercial grade business users, stability and response speed are less critical to researchers, but the ease of use and functionality are more important.

It is ironic to see that "metadata creation and editing" is considered the least important here by the same group of users who collectively reported "Find information about data in WorldMap" as the most frequently used activity on this platform. This is a common dilemma not just for WorldMap, not even just for web mapping systems, but for all GIS operations everybody needs metadata in order to find and selectively use data created by others, but very few would like to contribute to metadata creation. This problem cannot be solved by a usercentered design of online GIS systems alone. But making metadata editing easier could help, so could making data search results more dependent on metadata, and visibly so, which will help educate users on how important metadata is.

Question 4 revealed an unexpected phenomenon - almost half of the users have stopped using the system for some reason. However looking at the detailed responses, the result is quite meaningful. Among the 140 who have stopped, 51 of them gave an "Other" answer which include don't need it any more, finished the work, can't find time to use it again, etc. This is likely a reflection of the nature of the research community.

\section{Figure 5 Why stopped using WorldMap}

The users' professions and disciplines reported in the survey presents a truly diverse composition as shown in Figure 6. Humanities professors and students are the largest groups, but consists only $7 \%$ of the total responses. Because the multiple choices are not set to be exclusive, allowing one person to select multiple roles, the number of responses is 2.4 times more than the number of people who responded to this question. This means that many people selected several roles, such as being a professor in both social science and health, or being an engineering business person as well as an IT student, and perhaps a geography hobbyist too.

Figure 6 WorldMap user's profession and discipline composition

Regardless of the professions and disciplines, almost half of the responses indicate that research was the main reason for using WorldMap. The second most popular reason is teaching, but only at $14 \%$. See Table 5 for the complete breakdownn of the reasons. 


\section{Table 5 Main reason for using WorldMap}

About $43 \%$ of respondents consider themselves regular GIS users, but less than $10 \%$ say they are regular WorldMap users (Figure 6). More than half consider themselves occasional WorldMap users. Those who say they have never used WorldMap probably mean they have never used it before, and should be considered equivalent to first time WorldMap users. If the survey administration software had allowed it, the authors would have eliminated the "Never used WorldMap" option from the questionnaire, since everybody receiving the survey invitation would have at least requested a WorldMap user account. We assume that people who never used the system would not bother to register for an account, let alone fill out the survey.

\section{Table 6 Level of experience with GIS and WorldMap among survey respondents}

The fact that $40 \%$ of the survey respondents discovered WorldMap through an Internet search perhaps indicates that a significant portion of the potential users for such a web mapping system are actively looking for a solution to their needs. Another $21 \%$ were led to the system by their colleagues or friends (Table 7). This means that the WorldMap team's outreach effort accounts for less than half of the usage on the system. This is actually consistent with the minimum outreach activities the WorldMap team had engaged in, due to budget limitations and work load priorities.

\section{Table 7 How users discovered WorldMap}

There is only one male user who is under 18 years old among the 282 respondents, probably a college freshman or high school student. The age and gender distributions of the respondents resemble that of a typical work force, with slightly higher participation from seniors above 65 years of age (Figure 7). Again, this may be a reflection of the research community in higher education institutions, where tenured faculty members often work beyond typical retirement age.

\section{Figure 7 Age and gender composition of WorldMap users}

\section{Cross examination of the responses}

The initial review of the survey results answered many of the authors' questions, but also raised new questions:

- Does GIS experience matter when it comes to finding WorldMap easy to use?

- For those users who find WorldMap difficult to use, did they consult the various help resources?

- Who is contributing data? Who is good at contributing data?

- What groups care most about access control?

- What groups care most about the functionality of the system?

- Does WorldMap serve one purpose better than others?

The list of questions can go on much longer, and there are many ways in which the survey responses could be used to infer answers to additional questions. The authors have only just begun this exploration using a few exemplary questions in this section, but we have also constructed a generic cross tabulation tool in Microsoft Excel containing all of the original survey data, which we will share freely with anyone who would like to continue this exploration.

The generic cross tabulation tool allows users to pick from a pull-down list any of the 231 possible choices provided by the survey form (ignoring all type-in text answers) as any of 
the columns and rows of a summary table. Embedded Excel formula will programmatically populate the table cells by counts of respondents who answered with both of the choices defined by its column and row. This table can have as many columns and rows as the authors would like to have (up to 231), and in any order desirable.

For example, to answer the first question above, the authors selected the columns to be GIS experience levels, and the rows to be easiness in using WorldMap to find and use someone else's map. The summary table is populated by the Excel tool as shown in Table 8 .

It is interesting to see that although a vast majority of regular GIS users finds this activity very easy or easy, there are some who find it difficult or very difficult; meanwhile people who never used GIS have a more even chance of finding this activity easy or difficult.

Table 8 Example of the generic cross tabulation tool for survey results exploration - GIS experience level vs. easiness in using WorldMap to find and use someone else's map

The same data in Table 8, plus similar data about creating new maps, are used to generate figure 8 . It is evident that among users finding these activities easy, a higher percentage of them are regular GIS users. This is even more the case for creating maps than for using someone else's maps. However, a lack of GIS experience is by no means an obstacle to using WorldMap functions with ease; and regular GIS experience is by no means a guarantee that the system will be easy to use either.

Figure 8 GIS experience level vs. easiness in using WorldMap to find and use others ' map or create new map

Very few users consider themselves regular WorldMap users. Most are either occasional users, or first time users, thus their WorldMap level of experience does not seem to have much relationship with their self-defined ease in using the system for either finding and using someone else's map, or creating their own maps (Figure 9).

Figure 9 Level of experience in WorldMap vs. easiness of using and creating maps

Do users consult the help resources more when they find the system hard to use? To answer this question, the authors selected the two most readily available types of help resources - online video and PDF document, and the two most common activities - finding and using someone else's map and creating a new map. The cross tabulation summary is shown in Table 9. The table shows a slight increase in the help resource usage level among people who consider these activities difficult or very difficult. This means that more users who are using the system with ease didn't have to consult the help resources. However there is also a sizable number of users who consider these activities difficult, yet never bothered to use the help resources available online.

Table 9 Type of help resource usage rate vs. ease of using WorldMap

Users who have consulted the help resources but still find the system hard to use are more likely to feel the resources not helpful, as shown in Figure 10. However regardless of their system usage experience, a majority of the users consulted the online help files, and found them helpful.

\section{Figure 10 Helpfulness of online resource to users with different experience in creating maps}

Most data layers in WorldMap are contributed by users rather than by the platform development team. The authors have a strong interest in understanding who contributes data to WorldMap; and who is having difficulty when attempting to contribute data.

Figure 11 and 12 show the disciplinary and professional composition of data contributing users. Geographers are leading and having an easy time contributing data, followed by 
planner/designers, environmental scientists and IT professionals. Researchers in humanities and social sciences are major data contributors too; however some of them are struggling.

Users from government agencies lead in data contribution; perhaps most of them are geographers and GIS professionals creating public data. Professors, research associates and students closely follow. Some students, non-profit agency workers and hobbyists find data contribution more difficult than others.

Figure 11 Data contributing users by discipline

Figure 12 Data contributing users by profession

After users contributed data to WorldMap, which users care about access control? Figure 13 show that most of the users do care and most of them find access control easy to set in WorldMap. The exception is the citizen scholars or hobbyists; most of them have never tried setting access control for data. Some government workers find it difficult to control data access. Further analysis is required to determine how many of them are the major data contributors revealed above, and why they find the function hard to use. One possibility is that their expectation on access control might be different from that of the research community.

\section{Figure 13 User professions vs. ease of controling access to data}

Figure 14 shows that more geographers find the access control function easy to use than do users in other disciplines. Very few users in any discipline find the function very difficult, but many have not used it yet.

\section{Figure 14 User discipline vs. ease of controling access to data}

Does WorldMap serve one purpose better than others? Figures 15 and 16 show that about the same percentage of instructors and researchers find it easy or difficult to use maps or create maps in the system. People who are using it for course assignments, i.e. students, have a somewhat more difficult experience, which is probably due to the students' lack of experience or time to learn the system, while people who are using it on the job, i.e. working professionals, have a little easier experience. The hobbyists have the lowest satisfaction rating on these activities, even though more than half of them still consider it easy to use the system.

Figure 15 Ease of finding and using maps for different purposes

It is apparent that the WorldMap system serves teaching, learning, and research activities at a similarly effective level, though there are far more people using the system for research than for other purposes.

\section{Figure 16 Ease of creating maps for different purposes}

Most of the users have tried to look for information about the data, indicating that they care about data quality. However, who are the users who most likely will use the feedback functions in the system to contribute to data quality measurements? Figure 17 and 18 show the distribution of such activities across the disciplines and professions.

Figure 17 Use of the feedback function in WorldMap bydiscipline

The engineers used this function the most (a little over 60\%), and users engaged in the humanities used it the least (about 40\%). The research associates and government workers used it the most (over 60\%), and the hobbyists used it the least (about 35\%).

Figure 18 Use of the feedback function in WorldMap by profession 
As shown in Figure 19, government workers are the most demanding in terms of system functionality, while students are the most satisfied. There is no visible difference between different disciplines as to their opinions and experiences of the WorldMap functions.

\section{Figure 19 Users in different professions vs. their opinions on system functionality}

Our survey was only sent to WorldMap users, and we did not find in the literature comparable survey results on other web mapping systems, therefore findings from this analysis apply directly to the WorldMap user community only. However the authors believe that some of the patterns and relationships discovered are generic and applicable to other similar web mapping systems, such as the different preferences and level of satisfaction among users with different GIS background, in different disciplines, and for different purposes.

Even though the authors considered applying statistical analysis to this survey dataset, we decided not to include such work in this paper. The main reason is that by computing the simple counts and percentages, and visualizing the data through charts and graphics, trends and relationships in the data are already displayed clearly for the targeted questions we attempted to address. However the authors did not intend to depict all meanings contained in the survey dataset through this single paper. In the future, the authors may apply statistical analysis to possibly refine the conclusions presented here and to develop answers to additional questions.

\section{Conclusions and further research}

The survey results show that WorldMap users make up a diverse group by age, gender, profession, discipline, and nationality. More than half are not regular GIS users, and over a quarter are first time GIS users. This survey provides quantitative evidence that a significant portion of successful WorldMap users are indeed people without any previous GIS experience. The system serves a broad range of disciplines and professions, as it was originally intended to do by the project team from the beginning. In this way, WorldMap appears to be lowering technical barriers to making use of spatial information, and collaborating with such material (Guan and Lewis 2011).

This survey reveals that most WorldMap users are occasional users. Almost half of them used it for some purposes, and then stopped for some reason. The fact that they participated in this survey indicates that they may still be connected to the user community and may return to the system once they have a need for it in the future. It may be the case that when web mapping platforms are made accessible and easy to use for non-GIS professionals, the occasional users who do not need to make maps every day but nonetheless have the need for doing so once a while, will form the largest user base. When they do use web mapping systems, they not only look for data to make their maps, but also upload their own data to use in their maps. By doing so, they contribute data for others to use. Most of this type of user will look for metadata about data they find and want to use, but many will not have the time and desire to create metadata for their own uploaded data. For them, ease of use is concerned key characteristic.

These findings provide valuable references to the WorldMap development team for prioritizing their limited resources in future maintenance and improvement of the system. For example, funding and staff time should be put more into conducting a usability test and user interface design revision, rather than into purchasing bigger and more powerful servers for faster performance and higher system uptime. User support should be more focused on providing better online help materials which everybody has equal access to, rather than holding face-to-face help sessions which only a small percentage of users can attend. 
Metadata editing and data quality commenting processes should be streamlined to encourage and help users contribute metadata with less effort. The current training workshop of GIS for Humanists is much needed, and should be continued and strengthened.

These findings also shed light on the rapidly expanding online GIS user community as a whole. The majority of survey participants discovered WorldMap from an Internet search. They would have found other online GIS systems too, and could have used them if WorldMap had not meet their needs. Their usage patterns, preferences, professional and demographic compositions, as well as expectations on the online mapping system are all relevant to other online GIS systems' development. Even though the data in this study has inherent limitations to one system only, the understanding of today's online GIS user needs to start from somewhere concrete. In this paper, when appropriate, we try to be clear in drawing conclusions, about when they apply to WorldMap and when online GIS at large. We wish to see an expansion of this user study into other web mapping systems in the future.

Using a user-centered design approach in developing and improving an online mapping system helped us to better understand the users, their needs and the limitations on their side and on the side of the system itself. The approach aided us in preparing the next steps in the development and implementation of WorldMap. In the future we will consider testing other methodologies for working with users, such as guided workshops, experiments involving users, or perhaps even a usability game in which the users could express their wishes and needs in a playful way. WorldMap, like other online mapping systems, will continue to evolve, driven by both technology advancements and our understanding of evolving user needs.

\section{Acknowledgements}

The WorldMap project is partially funded by the U.S. National Endowment for the Humanities Digital Humanities Implementation Grants, Award No: HK-50091-13. For a complete list of sponsors, please see the "Sponsors" page on http://about.worldmap.harvard.edu/.

\section{Bibliography}

Andrienko, N., G. Andrienko, H. Voss, F. Bernardo, J. Hipolito, and U. Kretchmer. 2002. Testing the Usability of Interactive Maps in CommonGIS. Cartography and Geographic

Information Science 29 (4): 325-342. doi:10.1559/152304002782008369.

Butler, K. A., 1996, Usability Engineering turns 10, Interactions, 3(1), $59-75$.

Çöltekin, A., B. Heil, S. Garlandini, and S. I. Fabrikant. 2009. Evaluating the Effectiveness of Interactive Map Interface Designs: A Case Study Integrating Usability Metrics with

Eye-Movement Analysis. Cartography and Geographic Information Science 36 (1): 5-17. doi:10.1559/152304009787340197.

Edsall, R., G. Andrienko, N. Andrienko, and B. Buttenfield.2009. Interactive Maps for Exploring Spatial Data. In The ASPRS Manual of GIS, edited by M. Madden.

Fabrikant, S. I., S. Rebich-Hespanha, N. Andrienko, G. Andrienko, and D. R. Montello. 2008. Novel Method to Measure Inference Affordance in Static Small-Multiple Map Displays Representing Dynamic Processes. The Cartographic Journal 45 (3): 201-215. doi:10.1179/000870408X311396. 
Guan, W. W.. Bol, P. K, Lewis, B. G, Bertrand, M.R., Berman, M. L., \& Blossom, C. J. 2012. WorldMap - a geospatial framework for collaborative. Annals of GIS, 11(52), 121-134.

Harrower, M., and B. Sheesley. 2005. Designing Better Map Interfaces: A Framework for Panning and Zooming. Transactions in GIS 9 (2): 77-89. doi:10.1111/j.14679671.2005.00207.x.

Haklay, M., and C. Tobón. 2003. Usability Engineering and PPGIS: Towards a User-Centred Approach. International Journal of Geographical Information Science (IJGIS) 17 (6):577-592.

Haklay, M., and A. Zafiri. 2008. Usability Engineering for GIS: Learning from a Screenshot, Special Issue on Use and User Issues. The Cartographic Journal 45 (2): 87-97. doi:10.1179/174327708X305085.

Hegarty, M. 2004. Commentary: Dynamic Visualizations and Learning: Getting to the Difficult Questions. Learning and Instruction 14: 343-351. doi:10.1016/j.learninstruc.2004.06.007.

Hegarty, M. 2013. Cognition, Metacognition, and the Design of Maps. Current Directions in Psychological Science 22 (1): 3-9. doi:10.1177/0963721412469395.

Hewett, T. T., Baecker, R. M., Card , S. K., Carey, J. G. Gasen, M. M. Mantei, G. Perlman, G. W. Strong and B. Verplank, 2002, Curricula for Human-Computer Interaction. http://www.acm.org/sigchi/cdg/cdg2.html\#2_1, Accessed May 2014.

Koua, E. L., A. M. MacEachren, and M. J. Kraak. 2006. Evaluating the Usability of Visualization Methods in an Exploratory Geovisualization Environment. International

Journal of Geographical Information Science 20: 425-448. doi:10.1080/13658810600607550.

Krug, S. 2000. Don't Make Me Think: A Common Sense Approach to Web Usability. Berkeley, CA: New Riders.

Lewis, B. G. \& Guan, W. W. 2011. Jump-starting the next level of online geospatial collaboration: Lessons from AfricaMap. In Li, Dragicevic, \& Veenendaal, Advances in Web-based GIS, Mapping Services and Applications (S. 255-276). London: Taylor \& Francis Group.

MacEachren, A. M., and M.-J. Kraak. 2001. Research Challenges in Geovisualization. Cartography and Geographic Information Science 28 (1): 3-12. doi:10.1559/152304001782173970.

McCarthy, J., and P. Wright. 2004. Technology as Experience. Cambridge, MA: The MIT Press.

Medyckyj-Scott, D. 1993. Designing Geographical Information Systems for Use. In Human Factors in Geographical Information Systems, edited by D. Medyckyj-Scott and H.

Montello, D. R. 2009. Cognitive Research in GIScience: Recent Achievements and Future Prospects. Geography Compass 3(5): 1824-1840. doi:10.1111/j.17498198.2009.00273.x.

Nivala, A.-M., S. Brewster, and L. T. Sarjakoski. 2007. Usability Problems of Web Map Sites." In Proceedings of 23rd International Cartographic Conference, Moscow, August 4-10. Accessed November 15, 2014.

http://icaci.org/files/documents/ICC_proceedings/ICC2007/html/Proceedings.htm 
Nivala, A.-M., S. A. Brewster, and L. T. Sarjakoski. 2008. Usability Evaluation of Web Mapping Sites. Special Issue on Use and User Issues of The Cartographic Journal 45 (2): $130-140$.

Norman, D. 2002. The Design of Everyday Things, Basic Books, New York, USA.

Norman, D. 2004. Emotional Design: Why We Love (or Hate) Everyday Things, Basic Books, New York, USA.

Nyerges, T. L. 1993. How Do People Use Geographical Information Systems? In Human Factors in Geographical Information Systems, edited by D. Medyckyj-Scott and H.

Poplin, A. 2015. How user-friendly are online interactive maps? Survey based on experiments with heterogeneous users, Cartography and Geographic Information Science, http://dx.doi.org/10.1080/15230406.2014.991427.

Roth, R. E., and M. Harrower. 2008. Addressing map interface usability: Learning from the Lakeshore Nature Preserve Interactive Map. Cartographic Perspectives 60 (Spring):4666.

Roth, R.E., Ross, K.S., Finch, B.G., Luo, W. and A. M. MacEachren. (2010). A user-centered approach for designing and developing spatiotemporal crime analysis tools, Proceedings of the 6th International Conference, GIScience 2010, Zurich, Switzerland, September 1417, 2010, Fabrikant, S.I., Reichenbacher, T., van Kreveld, M., Schlieder, C. (Eds.)

Roth, R. E. 2013. Interactive Maps: What We Know and What We Need to Know. Journal of Spatial Information Science 6: 59-115.

Slocum, T. A., C. Blok, B. Jiang, A. Koussoulakou, D. R. Montello, S. Fuhrmann, and N. R. Hedley. 2001. Cognitive and Usability Issues in Geovisualization. Cartography and Geographic Information Science 28: 61-75. doi:10.1559/152304001782173998. 